\title{
MERGER OR ACQUISITION? INTRODUCTION TO THE HANDBOOK OF HISTORICAL ECONOMICS
}

\author{
Alberto Bisin \\ Giovanni Federico \\ Working Paper 28786 \\ http://www.nber.org/papers/w28786 \\ NATIONAL BUREAU OF ECONOMIC RESEARCH \\ 1050 Massachusetts Avenue \\ Cambridge, MA 02138 \\ May 2021
}

Prepared for the Handbook of Historical Economics, edited by Alberto Bisin and Giovanni Federico, Elsevier, forthcoming 2021. The views expressed herein are those of the authors and do not necessarily reflect the views of the National Bureau of Economic Research.

NBER working papers are circulated for discussion and comment purposes. They have not been peer-reviewed or been subject to the review by the NBER Board of Directors that accompanies official NBER publications.

(C) 2021 by Alberto Bisin and Giovanni Federico. All rights reserved. Short sections of text, not to exceed two paragraphs, may be quoted without explicit permission provided that full credit, including $(\odot$ notice, is given to the source. 
Merger or Acquisition? Introduction to the Handbook of Historical Economics Alberto Bisin and Giovanni Federico

NBER Working Paper No. 28786

May 2021

JEL No. B40,N00

\begin{abstract}
$\underline{\text { ABSTRACT }}$
The relationship between history and economics as academic disciplines is methodologically subtle and sociologically contested. If the Cliometric revolution can be characterized as an acquisition of economics by history, the most recent trends in Historical Economics appear to turn this relationship on its head. In this Introduction we read the chapters of the Handbook as a forceful argument in favor of a merger between the two disciplines rather than the acquisition of one by the other; a merger which combines, notably, the detailed knowledge of historical sources, the capability of distilling complex historical processes into a model, and the statistical/ econometric skills for identification and estimation.
\end{abstract}

\author{
Alberto Bisin \\ Department of Economics \\ New York University \\ 19 West 4th Street, 5th Floor \\ New York, NY 10012 \\ and NBER \\ alberto.bisin@nyu.edu \\ Giovanni Federico \\ Social Science Building (A5) \\ NYU Abu Dhabi, Saadiyat Campus \\ PO Box 129188 \\ Abu Dhabi \\ United Arab Emirates \\ gf63@nyu.edu
}




\section{Historical Economics}

Economists have always looked at history for insights. Adam Smith used historical evidence so extensively in the Wealth of Nations that "on top of being the founder of modern economic thinking, [he] could also be regarded as one of the first modern economic historians" [Manioudis and Milonakis (2020)]. However, the study of economic history became an established academic field only about a century later and for most of the 20th century it remained an historical discipline.

Historical Economics was born arguably in the 1960s, with the so-called Cliometric revolution; Margo (2021). We think of Cliometrics as an acquisition of economics by history in the sense that historians trained in economics started to use formal economic reasoning and statistical testing to tackle big issues, such as the efficiency of slavery (Conrad and Meyer, 1958; Fogel and Engerman, 1974); or the contribution of railways to American economic growth; Fogel (1964). In the following decades, Historical Economics spread quickly in the United States and more slowly in Europe; Cioni et al. (2021). Now, arguably, a second revolution is unfolding, as the field is attracting the renewed interest of economists. It is generally difficult to identify the orgins of a change of paradigm in a field, but in this case we should certainly cite the early contributions of Douglas North (North and Thomas (1973)) and Avner Greif (Greif, 1989, 1993) on institutions, as an inspirational trait d'union with the pathbreaking empirical approach in e.g., La Porta et al. (1998) and Acemoglu et al. (2001). . $^{2}$

The most evident novelty in Historical Economics at this turn, the sense in which we think of this as an acquisition of history by economics, lies in the radical shift in the research questions: the Cliometricians studied the economic past for the sake of its knowledge, while most recently Historical Economists often search in the past the answer to questions about current economic conditions. This general research agenda, which is referred to as Persistence Studies, has flourished recently, tackling on issues ranging from the effects of the colonial forced labour in Peru (Dell, 2010) to those of location of portage sites (transhipment between different means of transportation) on urban geography of the United States (Li et al., 2012). At the same time modern work in Historical economics is also characterized by resorting to state-of-the-art econometrics to identify causal relationships and by a more explicit

\footnotetext{
${ }^{1}$ Robert Townsend's book on general equilibrium modeling of the econonomy of an English manor (Townsend, 1993) can also be considered an early gem in Historical Economics, though it arguably had less of an impact in the development of the field.
} 
relationship between empirical analysis and theoretical models. The essence of the new wave is well represented by the work of Daron Acemoglu, James Robinson and co-authors on the role of institutions in economic growth. On the one hand, their pioneering study in the field, Acemoglu et al. (2001), aims at identifying the causal effects of a past historical event (the different types of colonial institutions) on a current outcome (GDP per capita in 1995). The Instrumental variable approach they adopt, and the clever choice of the instrument (settlers' mortality), have been wildly popular in later work in Historical economics. ${ }^{2}$ On the other hand, their work on institutions has been supported by a conspicuous effort in developing theoretical models about institutional change - surveyed in (Acemoglu et al., 2021) - which also has spurred a lot of work in the discipline.

Finally, one other perhaps less prominent but nevertheless essential feature of important aspect of recent work in Historical Economics is the expansion of the boundaries of the discipline beyond economic themes as traditionally intended. ${ }^{3}$ Historical Economists have dealt with political science issues such as the effect of compulsoring voting on political participation (Bechtel et al., 2016), the determinants of the rise to power of Nazi party in Germany (Adena et al., 2015; Satyanath et al., 2017; Voigtländer and Voth, 2014) and of the Fascist party in Italy (Acemoglu et al., 2020), or the effects of American bombings in Vietnam (Dell and Querubin, 2018).

In the meanwhile, scholars have continued to pursue the more traditional postCliometric research agenda. First and foremost, they have greatly enhanced our knowledge of past economies but they have also gained new insights tackling "traditional questions" in history by exploiting suitable advances in economics, econometrics and computing power. For instance, Becker and Woessmann (2009) have given a new interpretation to the Weber thesis about the positive consequences of the Reformation on economic growth of Prussia. He argued that the Protestant ethic fostered development, while Becker and Woessman show that the Reformation increased human capital becuase Protestants were asked to read the Bible by themselves instead of relying on the clergy's interpretation. ${ }^{5}$

\footnotetext{
${ }^{2}$ The turn of Historical Economics towards causal analysis is consistent with the recent empirical turn in economics and is largely prevalent in the recent work, even if formal dynamical models are used as well (Nunn, 2020).

${ }^{3}$ This is also consistent with a trend in economics - which is at times accused of an "imperialist attitude" towards social sciences in general.

${ }^{4}$ Some years ago, some of these Persistent Studies have been collected in a book evocatively titled The long economic and political shadow of history, Michalopoulos and Papaioannou (2017).

${ }^{5}$ Other interesting examples of new takes on traditional questions include: Alesina et al. (2013a)
} 
In short, Historical Economics is a lively broad field of study with a glorious past and an exciting and challenging future. This Handbook tries to present the current frontier and to serve as a guide for future research on the field. We aim at offering a balanced view of the field, with its peculiarities, its scientific achievements, but also its shortcomings. In the end, the specific comparative advantages of history and economics which in our opinion the chapters distill and identify provide a forceful argument in favor of a merger between the disciplines along these lines.

The first three chapters (Part One of the Handbook) outline the evolution of the discipline as sketched out in this Introduction (Margo, 2021; Cioni et al., 2021; Nunn, 2021). Part Two deals with Sources, Methods, and Models of Historical Economics. A few of the chapters collected here illustrate and discuss the data sources researchers are developing and using in the field, including e.g., the new uses of traditional sources, such as censuses and maps (Giuliano and Matranga, 2021), archeological (Pascali and Matranga, 2021) and anthropological data (Lowes, 2021). Other chapters in Part Two focus on the use in Historical Economics of statistical and econometric methods for causal analysis developed in economics (Valencia, 2021; Cantoni and Yuchtman, 2021; Voth, 2021; Bisin and Moro, 2021; Hansen et al., 2021; Monnet and Velde, 2021). These chapters highlight the variety of methods successfully exploited in the field, from causal inference (Regression discountinuity, Instrumental Variable analysis, Natural Historical Experiments, ..) to formal structural methods. Part Two contains also a series of chapters on the theoretical analysis of institutional change. As we already noticed and will discuss later in this Introduction, institutions have been at the core of Historical Economics and much empirical work has been devoted to this issue. But the study of institutions in historical analysis is very complex - how are they defined, how they change, how they are measured - and it requires analytical frameworks of reference which theoretical work is attempting to provide. Five chapters in this section of the book (Acemoglu et al., 2021; Bowles et al., 2021; Levine and Modica, 2021; Persson and Tabellini, 2021;

who confirm Ester Boserup's thesis regarding the origins of gender role differences in different forms of agriculture practiced traditionally (specifically, shifting and plough cultivation); Juhász (2018) who finds strong evidence for the classic hypothesis that industry protection reduces technological adoption by studying the effects on the development of the French cotton industry of the differential effectiveness of Napoleonâs continental blockade on the North and the South of France; Squicciarini and Voigtländer (2015) who document a strong relationship between economic growth and endowment of high end human capital in early 19th century France (measured with the subscriptions to the Encyclopedie), as predicted by traditional growth theory in economics (Barro et al., 1995; Acemoglu, 2012). 
Bisin and Verdier, 2021) provide a careful and comprehensive survey of the different approaches and results. Part Three of the Handbook contains a selection of results of Historical Economics. Of course it would have been impossible to cover all (or even most) results in the field. More modestly, the chapters in Part Three aim at giving a flavor of the recent work in Historical Economics. It contains, in the tradition of the Handbook series, several surveys of some major field of research: the development of commodity markets (Federico, 2021), the economic history of Africa (Frankema, 2021), the economic history of religion (Becker et al., 2021), the consequences of foreign intervention after WWII (Matis et al., 2021), and monetary policy and banking (Monnet and Velde, 2021). It also includes four interpretative essays, which build on the authors' previous work (Ashraf et al., 2021; Broadberry, 2021; Clark, 2021; Mokyr, 2021) and a few case studies of new research work (Hall and Sargent, 2021; Stasavage, 2021; Greenwood et al., 2021). We have selected these latter not only for the historical relevance of the topics (respectively, the historical origins of the state, the funding of wars in United States history, the socio-economic effects of the diffusion of contraceptive technology); but also as examples of the range of methodologies used in Historical Economics - from the statistical and econometric analysis of historical series (Hall and Sargent, 2021) and spatial cross-sections (Stasavage, 2021) to the calibration of a dynamic structural model (Greenwood et al., 2021).

\section{Sources, methods, models, topics}

In this section we turn to a brief discussion of the chapters in the Handbook, to provide the reader with a more detailed roadmap of the various contributions it collects.

\subsection{Part one: The Evolution of the Discipline}

Margo (2021) outlines the origins and the development of Historical Economics from an institutional point of view, stressing the consequences for the profession. The Cliometric revolution was a reaction to the decline in standing of economic history after the mathematization of economics. Cliometricians tried to stave off this decline by adopting the approach and the methods of economics. They wanted to maintain the 'economic history' as a subfield of economics, as labor or development economics, as such they taught it in most undergraduate and graduate programs in economics. Their success was only temporary, and in the 1980s and 1990s the decline resumed. 
Nowadays, economic history as such as has all but disappeared in (almost) all $\mathrm{PhD}$ programs in economics. In constrast, the recent wave of Historical Economics is spearheaded by economists who deal with economic history issues, but as we said, are not necessarily interested in historical knowledge .

Cioni et al. (2021) provide quantitative evidence with regards to this narrative. They trace the success of the Cliometric revolution and of the new wave of Historical economics by looking at the publication record in top field journals, measuring the status of economic history as the share of all articles in the major economics journals. In a companion paper (Cioni et al., 2019) these authors document the large differences between top economics and top field journals in terms of issues and patterns as well as of citation numbers. Above all, they show that there is limited overlapping between the new wave of Historical Economics and the more traditional (post-Cliometric) economic history, and not only in the research questions. Even if all Historical Economists share the same methodological approach, few of them publish in both top field and general interest economics journals. ${ }^{6}$

The chapter by Nathan Nunn (Nunn, 2021) foresees the innovation of Historical Economics as pushing for a novel interpretation of historical phenomena. He argues that history should be interpreted along with a theory of biological and cultural evolution. This theory is well-developed in terms of formal models and Nunn (2021) argues that it provides for sharp implications in terms of our understanding of human capital, innovation, gender roles, the consequences of warfare, the effects of market competition, and more. Most generally, the theory of biological and cultural evolution has great explanatory power with with respect to the historical persistence of several socio-economic phenomena and hence it may be useful to address at its core the fundamental question of economic development, why is sustained economic growth often so elusive.

\subsection{Part Two: Sources, Methods, and Models}

The development and discovery of new data sources are a fundamental component of the contributions of Historical Economics. In recent years, scholars have collected and estimated a large number of new economic series, with a major effort to make them internationally comparable and easily available. On-line data-bases

\footnotetext{
${ }^{6}$ These differences will play a central role in our critical analysis of Historical Economics as a discipline, in Section 3, where we will explicitly make a distinction between "economic historians" and "economists" tout court.
} 
provide data on trade by country at constant and current prices since 1800 (Federico and Tena-Junguito, 2019) and on bilateral trade at current prices since the 1830s (Dedinger and Girard, 2017) Following the seminal work by Robert Allen (Allen, 2001) and (Allen, 2019), real wages are now routinely expressed in welfare ratios a simple and intuitive measure which can be compared across time and countries. Arguably, the most relevant contribution is the so called Maddison project, which continues the pioneering work by Angus Maddison (Bolt and Van Zanden, 2014; Fouquet and Broadberry, 2015; Broadberry, 2021) He started to collect series of national income since the 1980s (Maddison, 1991) and later converted them in 1990-PPP dollars (Maddison et al., 1995). Economic historians have since substantially increased the number of countries and have extended the series back in time to the Middle Ages. The work is going on, and new or revised series are added as soon as they available. In recent times Historical economists have widened the range of available data, as shown in the chapter by Giuliano and Matranga (2021). First, they show how modern technology has charged new versions of traditional sources, such as censuses and maps. Censuses have always been used as sources of aggregate data but the use of records was limited by their sheer size. ${ }^{7}$ The great increase in computing power has all but abolished this constraint, allowing researchers to link records from multiple U.S. censuses and trace the life pattern of individuals; see Abramitzky et al. (2019b,a). Similarly, geo-referencing has transformed maps from a visual static help into a source of information and variables for regression analysis. But Giuliano and Matranga (2020) show also the potential of 'new' qualitatively different sources, to address new research questions. Scientific research, for instance, offers a lot of new information on climate via tree rings and glaciers (Guiot et al., 2010) and on economic activity via lead deposits in glaciers (McConnell et al., 2018, 2019), even if publication in science journals might reduce their impact on the scholarly debate.

Matranga and Pascali (2021) provide a review of the data and the empirical methodologies developed to study the persistent effects of the very distant past on e.g., present-day living conditions and economic prosperity. Much of recent research in Historical Economics argues that these effects manifest themselves in local institutions and cultural traits which go back millennia. The scarcity of written records, as we move back in time, has pushed Historical Economists to study archaeological and paleoanthropological data. In this respect, Matranga and Pascali (2021) show

\footnotetext{
${ }^{7}$ The pioneering Gallman-Parker sample, for instance, was widely used in the early work on slavery but referred to only 405 cotton-producing counties from the 1860 U.S. Census.
} 
e.g., how archeological data have been successfully used to shed light on Neolithic revolution, the origins of state, and long-distance trade. ${ }^{8}$

For a number of reasons, the geographic coverage of archeological research is patchy: there are very many sites in Europe and the Mediterranean, some in Asia, but few in the America and very few in Sub-Saharian Africa. Furthermore, even when available, the archeological sources cannot document a wide range of activities, institutions and beliefs. Thus, scholars have widely resorted to ethnographic data, as Lowes (2021) shows and discusses in her chapter. The most notably source is Murdock's Ethnographic Atlas (Murdock (1967)), which collects information about primitive, historical, and contemporary societies, mostly from Africa and Northern America. More recently, Lowes (2021) reports, several economists working in Historical Economics have resorted to collect their own ethnographic data, following the practice and methods of anthropologists in the field; see e.g., De la Sierra et al. (2014), Lowes et al. (2017), and Lowes and Montero (2020).

Besides new sources, Historical Economics has brought new statistical and econometric methods to historical analysis, borrowing them from the causal inference literature in e.g., labor and development economics; see Angrist and Pischke (2008, 2014) and Cunningham (2021) for book treatments of this literature. The identification of causal relationships across history is central to Historical Economics, especially in the case of Persistence studies. The empirical focus of these studies centers, in the jargon of the causal inference literature, on the effects of a treatment variable taken-up in the historical past but whose effects persists in the present; e.g., high-quality norms or institutions. An exogenous historical factor may be available that directly affects the treatment variable and can be exploited as an instrument to identify causal effects. Form the point of view of formal statistical and econometric theory and practice, these exogenous historical factors can be studied with the use distinct methodologies; notably, Regression discountinuity design, Instrumental Variable analysis, and Natural Historical Experiments.

The chapter by Valencia (2021) surveys the research in Historical Economics employing either a Regression discountinuity design or Instrumental Variables, distinguishing between the seminal articles published from 2001 to 2011 and those belonging to second wave of studies, from 2012 to today (2020), which have introduced

\footnotetext{
${ }^{8}$ Archeological sources are also widely used in the current revival of Roman economic history, after having long been crippled by the disappearance of archives during barbaric invasions (Erdkamp, 2016).
} 
various refinements of these causal identification strategies. The studies surveyed in this chapter are quite impressive in terms of their breadth, studying the effects of several historical phenomena like the development of independent city-states in Italy from the 12 th century, the historical variation in land tenure patterns in colonial India, the redrawing of African national boundaries, the operation of the "Mita" forced labor system in colonial Peru and Bolivia, the invention and spread of the printing press, the role of media in support of democratic institutions, the bombing and counterinsurgency operations in Vietnam, the introduction of the steamship during the first wave of trade globalization.

Cantoni and Yuchtman (2021) survey instead the literature on Natural Historical Experiments. ${ }^{9}$ Consistently with the reading of Historical Economics we have given in this Introduction, they provide a useful taxonomy distinguising experiments i) to understand history - a traditional staple of economic historians, revised with the tools of modern econometrics; and experiments ii) to understand economics - where history supplies observations to test some economic theory to understand contemporary outcomes - i.e., Persistence Studies focusing on the effects of specific events in the past rather than on general economic characteristics. ${ }^{10}$ The breadth of the analyses and results surveyed in this chapter is also impressive: from the effects of historical phenomena like the Neolithic Revolution, the Columbian Exchange, the Marshall Plan, colonialism and slavery; to tests of the efficacy of infant industry protection, the existence of urban agglomeration effects, the incorporation of news in asset prices.

The chapters by Voth (2021) and Bisin and Moro (2021) take up the methodological challenge of extending the statistical and econometrics methods of causal inference to Historical Economics, and to Persistence Studies in particular. Voth (2021) makes two major points. The first is that persistence studies differ according to the similarity between the (current) outcomes and the (past) treatment . The causal inference is strong when the two measure the same feature ("apples and apples"), such as anti-semitism, which inspired Middle Ages pogroms in Germany

\footnotetext{
${ }^{9}$ See Diamond et al. (2010) for an interesting divulgative account of this method, containing various interesting examples. More generally, one can think of the current interest Natural Historical Experiments as an evolution of comparative history, whereby the exogeneity of the experiment is more formally addressed. An interesting example in this respect is the article by O'Rourke on the "Grain Invasion" of the European economy of the 1880s O'Rourke (1997). A sharp drop in transport costs caused the supply prices of American wheat all over Europe to collapse but European countries reacted differently. Some kept import free while others imposed heavy duties. O'Rourke estimates the impact of protection with a structural CGE model by comparing potential (under free trade) and actual (with protection) changes in functional distribution of income.

${ }^{10}$ See also Cantoni and Yuchtman (2020) for a complementary survey of this literature.
} 
and 20th century Holocaust. However, many studies ("apples and oranges"), relate different (past) treatments and (current) outcomes and thus their statistical results are more convincing if supported by modelling ("apples and oranges with theory"). Then Voth (2021) addressess the forceful critique of Persistence Studies recently put forth by Morgan Kelly (Kelly, 2019), arguing that it overstates the concerns about spatial correlation. Voth (2021) shows that most of the papers which Kelly (2019) quotes do control for spatial correlation by adding fixed geographical effects in at least one specification, without causing the results to become insignificant.

Bisin and Moro (2021) look at different methodological aspects of Persistence Studies. More specifically, they analyze the implications of allowing for heterogeneous treatment effects in Persistence Studies. More specifically, when treatment effects are heterogeneous, the research design identifies a Local Average Treatment Effect (LATE), rather than the Average (subject-level) Treatment Effect (ATE); see Angrist and Imbens (1995). Explicit models of the causal relationships to be studied in the context of the specific empirical analysis, help to clarify the interpretation of the identified causal effects and to put forward relevant new sets of questions, which can be addressed empirically, possibly with new data. In this respect Bisin and Moro (2021) propose minimal abstract models that help interpret results and guide the development of empirical strategies to uncover the mechanisms generating the effects, bridging causal inference studies and structural estimation methods in economics; along the lines, notably, of Heckman and Urzua (2010).

The explanatory power of structural models is particularly promising, Bisin and Moro (2021) suggest, in the study of the role of institutions on economic prosperity. As we already noticed, institutions have been at the core of Historical Economics; and much empirical work has been indeed devoted to the study of their effect on economic growth and prosperity, starting from the seminal papers by Acemoglu et al. (2001), Acemoglu et al. (2002). While this empirical work does not yet exploit structural models, a large theoretical literature has developed to address several fundamental questions which arise naturally in the empirical study of institutions in Historical Economics. Several chapters in this Handbook are devoted to surveying this theoretical literature.

Acemoglu et al. (2021) illustrate the issues involved in understanding institutional persistence and change by means of a simple conceptual game-theoretic framework which encompasses much of the authors' and others' theoretical work on the subject. This conceptual framework illustrates the strategic stability of institutions by identi- 
fying the forces behind âinstitutional stasisâ and the potential drivers of institutional change. Importantly, the theoretical analysis exemplified in this chapter provides an important justification for much of the empirical work on the Historical Economics of institutions by providing the rationale for why current institutions are shaped by past institutional choices, thus exhibiting âpath-dependent changeâ whereby initial conditions determine both the subsequent trajectories of institutions and how they respond to shocks.

In the class of "top-down" models studied by Acemoglu et al. (2021) institutional change is deliberately implemented by political elites either acting as a centralized authority or interacting with other competing political groups. In contrast Bowles et al. (2021) survey the "bottom-up" models, where changes in cultures and/or conventions are the result of the unintended and uncoordinated actions of a large numbers of actors with sparse information. This type of institutional change is akin to the transition from one equilibrium to another in an evolutionary equilibrium selection process. The dynamics in this class of models is illustrated by Bowles et al. (2021) with applications to a series of historic cases, including the emergence of private property and of the national bureaucratic state and the demise of serfdom. Most notably, they explore a key issue in world history, the Neolithic revolution â i.e., the transition from foraging to agriculture. This epoch-making change could be easily explained if agriculture were more productive and population was growing, as in the âstandard modelâ ((Weisdorf, 2005; Brooke, 2014), or if climate change made it more productive (Dow et al., 2009; Matranga, 2017). Bowles et al. (2021) aim to explain the stability of foraging societies and, above all, transition if agriculture were not more productive than foraging. They argue that, under some well defined conditions, societies shifted to agriculture because it offered better defined property rights and thus reduced internal conflicts.

Levine and Modica (2021) also study models of institutional dynamics or, more generally, of social organizations. They however concentrate their analysis on the long run changes brought about by one specific, but historically very important, mechanism: external competition and conflict. Indeed, historically, institutional success has occurred in the aftermath of invasion, warfare, and other form of conflict. The chapter by Levine and Modica (2021) then provides an analysis of models of conflict driven evolutionary theory, centered on their dynamic and stochastic properties, used to motivate the analysis of a broad range of historical phenomena. Evolutionary models are useful to select which of many feasible institutions and arrangements 
are persistent and hence observed in the long-run. They show, for instance that the simplest configuration resulting from conflict is a hegemony of the winner, with a single society ruling over an isolated geographical area. This is because of a form of complementarity of success in conflict: conquering a city or a province strengthens the winner and weakens the loser. They then argue that i) hegemonies have in fact been more common and persistent in the last two millennia than one would expect; ii) where and when they have not been prevalent (e.g., in Europe and India), outsider societies have played a decisive role. Furthermore, the models studied by Levine and Modica (2021) have explanatory power to distinguish conditions under which, in the absence of hegemony, competing societies are extractive or rather inclusive.

While several earlier empirical studies in Historical Economics appeared to run races between the explanatory power of institutions and culture (as well as history, geography, and other factors) for economic growth and prosperity, it is now more common to stress the importance of the interaction between institutions and culture to this effect. Both Persson and Tabellini (2021) and Bisin and Verdier (2021) take this view in their chapters. They define culture as individual values and preferences and model its dynamics in a society as the outcome of evolutionary selection mechanism, along the lines of the models of the models surveyed by Bowles et al. (2021). Both chapters also consider institutional change as the result of the interactions between elites and other political groups, along the lines of the models surveyed instead by Acemoglu et al. (2021). Persson and Tabellini (2021) construct their survey gradually building layers of complex interactions on one specific simple model of political agency. It highlights the joint effects of culture and institutions on policy outcomes by studying the mechanisms politicians adopt to extract rents from the political process at the voters expense. More specifically, in this context, institutions are represented by formalized rules of the socio-economic interaction between political groups, such as the rules for political and judicial procedures.

Bisin and Verdier (2021) take instead a more abstract approach to the study of the interaction of culture and institutions, showing how the combination of models of institutional dynamics with models of cultural dynamics can generally be projected into a useful representation of these interactions, as a system of differential/difference equations represented by a phase diagram. They focus on some general properties of these system which matter for the comparative dynamics of culture and institutions and for the response of the system to exogenous shocks, e.g., natural historical experiments. Indeed, Bisin and Verdier (2021) show how these general properties depend 
in a fundamental way on whether culture and institutionas are complementary or substitutes in the dynamical system. The chapter also illustrates these methods and concepts by means of a simple analytical example from Bisin and Verdier (2017), studied and solved in some detail. it singles out conditions under which the cultural and institutional dynamics, between groups with different propensities to act violently in a conflictual society, favor or hinder the development of a legal system for the protection of property rights.

It would be easy to conclude from our discussion up to this point that structural estimation methods are still not as extensively used in Historical Economics as they are e.g., in several sub-fields of economics, from industrial organization (Reiss and Wolak, 2007) and labor economics (Keane, 2010); to political economy (Merlo, 2005). On the contrary, the realm of applications of structural methods in Historical Economics is quite vast in the context of traditional dynamic macroeconomic questions. Early pathbreaking attempts, such as the books by Jeffrey Williamson on American economic growth and inequality in Britain (Williamson et al., 1974; Williamson, 1985) might have had relatively little following, methodologically. But in more recent times Historical economists have used structural estimation and calibration methods, exploiting constructed historical datasets. These work shed new light on important historical episodes by using diagnostic methods that help identify potential classes of models for evaluating important historical events and by quantifying the impact of different shocks on macroeconomic activity during historical periods. The chapter by Hansen et al. (2021) surveys these methods, with two important historical episodes as examples of their applicability: the Industrial Revolution and the U.S. economy from 1889-1929, forty crucial years which featured World War I, two major financial panics, the diffusion of electricity and the internal combustion engine and the 'Roaring Twenties", which immediately preceded the Great Depression.

In their chapter, Monnet and Velde (2021) survey the applications of Historical Economics to the study of money, banking, and financial intermediation, a sub-field where structural models are prevalent. They construct a straw man of Historical Economics as dominated by causal inference, lacking structural methods, and argue that this is not - and should not be - the case in their sub-field. The study of the effects of monetary policy, in particular, is mostly about identifying the data generating process over time, that is, typically a stochastic dynamic general equilibrium model, rather than identifying marginal effects of specific events. ${ }^{11}$ Monnet and

\footnotetext{
${ }^{11}$ They grant Friedman and Schwartz (1963) with the early formulation of their methodological
} 
Velde (2021) notably highlights the evolution of the literature, especially on financial development and financial crises. Recent works display trend towards understanding the diversity of development models and financial systems and the microeconomic sources of aggregate fluctuations. Structural models appear particularly central in their review of the literature on the roots of high inflation in the 1970s.

\subsection{Part Three: Topics}

There are dozens of interesting and exciting topics in Historical Economics worthy of a survey in the Handbook. In an attempt to avoid expanding the size of the Handbook well above the reasonable, we have selected just a few which we deem representative of the different strains of the field and of their distinctive methods. Furthermore, we have selected topics which have not been recently surveyed in other published material - to which we explicitly refer here instead: ${ }^{12}$ Meissner (2014) on globalization and growth, Deng (2014) on China, Johnson and Koyama (2017) on state capacity, Abramitzky and Boustan (2017) on immigration in United States, and Crafts and Woltjer (2020) on productivity growth.

The chapter on development of markets (Federico, 2021) bridges two literatures: the well-established one on trade and trade policies and the fast growing one on market integration. So far they have remained separate and indeed they are the subject of two separate chapters in the Handbook of Cliometrics ((Lampe and Sharp, 2015; Federico, 2019). In the chapter for this Handbook, Federico (2021) argues that these two literatures deal with the same process with different measures, depending on available sources, respectively quantities or prices. He also argues that these literatures share strengths and weaknesses. For instance, we know a lot about trends (for trade, only since about 1800) and we have identified the causes of important changes in the process of development of markets, e.g., technological progress in transportation and political decisions about trade, but we have made few inroads about the effects of these changes. Conventional wisdom argues that development of markets and specialization have been a major source of (Smithian) growth but scholar are still struggling to find a way to measure their dynamic benefits.

After many decades of neglect by economic historians, Africa has become a hot

take on monetary history.

${ }^{12}$ The massive Handbook of Cliometrics (Haupert and Diebolt (2019)) surveys almost all major subjects in economic history (and also some minor ones), but it pays comparatively little attention to Persistence Studies and to non economic issues in the Historical Economics literature 
issue in Historical Economics. Several Persistence Studies deal with the long term effects of historical events such as the slave trade (Nunn and Wantchekon (2011)) and the diffusion of missions (Nunn (2014)). Other study the effects of culture and institutions on socio-economic development, e.g., in the Kuba Kingdom (Lowes et al. (2017). The survey by Michalopoulos and Papaioannou (2020) and the chapter by Fourie et al. (2019) in the Handbook of Cliometics, deal extensively with this literature. The chapter by Frankema (2021) brings a different perspective. He questions the African exceptionalism which ultimately motivates much of Persistence Studies. The recent economic history literature has shown that Sub-Saharian Africa was not uniformly poor and stagnant and has stressed the agency role of local population as opposed to the Eurocentric view of earlier works.

Becker et al. (2021) show how much Judaism, Christianity and Islam have shaped the economic and social life of Europe and the Middle East. The study of the socio-economic effects of religion is a booming field in Historical Economics, with a strong empirical turn, but the literature is "eclectic" and "fractionalized" (Becker et al. (2021)). Becker et al. (2021) in their survey stress the multiple interactions between religion and politics at the roots of differences in economic performance among religions and consequently among regions. The list of potential channels of transmission in this respect is quite varied: prosperity of Jews, Jewish persecutions, Protestant-Catholic differences, Muslim-Christian differences, human capital development, cultural attitudes, doctrinal differences, legal development, and financial development. In this respect, various recent contributions in Historical Economics pertain to the study of the causes of the "Long Divergence" between Middle Eastern and Western European economies from about the year 1000CE. In this respect, e.g., Kuran (2012) stresses the inability of the Muslim world to create or adopt those fundamental commercial and financial institutions which were responsible for significant socio-economic growth in the West, such as banking, the corporation (and corporate law), and institutions supporting impersonal exchange; Rubin (2017) centers on the use of Islamic religion by Middle Eastern rulers to consolidate their power stifling innovation (most notably the printing press) and economic growth. ${ }^{13}$

Last but not least, the chapter by Matis et al. (2021) is an example of the interdisciplinary bent of much of recent Historical Economics. As the authors note, interventions have been studied in "comparative politics, international relations, development economics, and political economy" - but historical economics offers some-

\footnotetext{
${ }^{13}$ See also, Blaydes and Chaney $(2013)$ and Bisin et al. $(2019,2020)$.
} 
thing additional. They focus on a clear research question (was foreign intervention a failure) and conclude that, although failures were very frequent, they were not the pre-determined outcome of interventions. The more pessimistic conventional wisdom depends to some extent on methodological flaws of some quantitative studies.

A series of other chapters we have selected to be added to this part of the Handbook offer topical reinterpretations of key topics in Historical Economics.

The research agenda of outlined in Ashraf et al. (2021) is a novel (some would say provocative) and controversial version of Persistence Studies. They argue that economic performance has been ultimately determined, in substantial part, by genetic heritage. They substantiate this claim by studying two historical drivers of genetic evolution. First of all, they show that migration of early humans out of Africa determined the amount of genetic diversity of different ethnic groups and hence of the different regions these ethnicities established themselves in. They then identify a causal relationship between genetic diversity and economic performance in the present. They argue that an intermediate level of diversity maximizes the chances of economic growth: too much diversity reduced trust, too little impacts negatively on the potential for innovation. The second driver of evolution studied by Ashraf et al. (2021) is the Neolithic revolution. After the birth of agriculture, natural selection favored individuals with pro-growth genetic characteristics who were more likely to survive and have many offsprings. They argue that this selection mechanism has favored various traits - e.g., a predisposition towards child quality, time preference, loss aversion, and entrepreneurial spirit, which in turn contributed to differential paths of technological progress, human-capital formation, and economic development across societies.

The chapter by Gregory Clark Clark (2021) is also an analysis of pro-growth behavior in societal development. Even though Clark refrains from a strictly genetic interpretation of behavior, a key component of his interpretation of the escape from Malthusian structures of pre-industrial society stands on the effects of differential fertility (Clark, 2007). The focus of his chapter Clark (2021) is on social mobility and, in this respect, the higher fertility of the rich has contrasting effects: it is good for the economy at large, because it increases the proportion of pro-growth individuals in the population; but it is not necessarily good for the offspring of the rich, as it made difficult for all of them to keep the high status of their forebears i.e., it caused downward social mobility for the former elites. To better understand this process Clark (2021) measures social mobility with the diffusion of rare (elite) 
surnames. He finds that this diffusion has been much slower than commonly assumed and has not accelerated after the Industrial revolution (Clark, 2014). But, as shown in this chapter, the process did work in the very long run: 'surnames of Norman origin, for example, had high status in England still in 1200-1400, but now are just slightly above average social status'.

The Industrial Revolution constitutes the second major watershed in world history, after the Neolithic revolution, and hence it represents one of the most intensely studied and interesting topics in economic history; see Crafts and Woltjer (2020) for a recent survey. The Handbook offers three different views of its origins.

Broadberry (2021), building on his earlier estimate of English GDP in the very long term Broadberry et al. (2015), highlights two peculiaties of England. It did not experience, unlike the rest of Europe (except Holland), a fall in GDP per capita when population recovered from the Black Death and the onset of the Industrial Revolution in the late 18th century was preceded by at least a century of slow growth in GDP per capita and of structural change, with a massive shift of occupation towards manufacturing and services: industrialization before the industrial revolution. Mokyr (2021) looks for the intellectual roots of the revolution in the early diffusion of the scientific method in Europe, which resulted in the subjection of all conventional wisdom to empirical testing. He argues that this intellectual approach was not just the prerogative of a small number of scientists, but it extended to practical inventors ("tweakers"). These latter were able to implement their ideas thanks to a large number of skilled artisans, trained in a quite efficient apprenticeship system.

The Industrial Revolution (1770-1867) is the key watershed of the narrative in Allen (2021), relating changes in technology, wages and the functional income distribution in the very long run. Allen (2021) argues that the high pre-industrial wages (relative to the cost of coal) stimulated labour-saving and energy-intensive technological change, which increased profits while wages stagnated. Then the tide turned, and for about a century capital-intensive technological progress in manufacturing raised wages for all workers. In the latest half a century, the rise of low-productivity low-wage services shifted again the distribution against workers, with exception at the very top of skill distribution. We have selected the three final research chapters to highlight the wide range of issues and methodologies of research in Historical Economics.

Hall and Sargent (2021) explore the sources of government financing for eight American wars and two insurrections, between 1812 and 1975, by the decomposing 
the changes in debt/GDP ratio between tax, debt (i.e., future taxation) and money creation (i.e., ultimately a reduction in the ex-post real returns to debt). They look at the data very closely through the eyes of two classic formal models of optimal government financing of (more or less permenet) surges of government expenditures. The two models (Barro, 1979; Lucas and Stokey, 1983) differ in terms of the set of financing instruments the government is assumed to have access to and have different implications regarding the composition of tax collection, adjustment of expost returns to government creditors and quantities of government debt, which are optimal after a fiscal shock: Barro (1979) requires an increase in both tax and debt (in fractions which depend on how permanent is the fiscal shock) but constant ex-post real returns; while in Lucas and Stokey (1983) all the adjustment operates through ex post returns to government creditors. By and large, the U.S. adopted an optimal tax smoothing policy (increase debt during wars and pay it later with taxation) and without affecting the returns to bondholders, in line with Barro (1979). But the U.S. has also seen negative wartime bond returns followed by positive postwar returns in the War of 1812, the Civil War, World War I and the Korean War as prescribed by Lucas and Stokey (1983). In conclusion Hall and Sargent (2021) give us a positive view of the explanatory power of even stylized formal economic models as narratives for how "policy makers over two centuries confront[...] their predicaments by combining their recollections of histories with their theories, [... how they...] struggle over and over again with the same economic and political forces.

The chapter by Stasavage (2021) on the origins of state is a typical example of the empirical turn in Historical Economics. The origin of the state is one of the oldest topics in history, but historians have not gone much beyond narratives with some plausible generalizations, such as states developed where agricultural surplus was greater. Stasavage (2021) instead contrasts a well-defined hypotheses of the origin of the state, the prevalence of storable cereals as main food staple which gives rise to the fundamental economic potential to support the economy of the state (Mayshar et al., 2019), with the invention, adoption, and diffusion of writing, as a technology central to governance ability. ${ }^{14}$ He finds that both hypothesis have explanatory power as factors for the origin of state, increasing roughly by the same amount (10-15\%) the likelihood of having a state. The main conclusion is that economic potential and governance ability have been complementary factors in the

\footnotetext{
${ }^{14}$ Writing is believed to have originated independently in Ancient Sumeria, among the Olmecs in Mesoamerica, and in China under the Shang dynasty.
} 
formation and development of states, from the earliest to modern nation-states.

Last but not least Greenwood et al. (2021) is a great example of the power of formal economic models in tracing the dynamics of the effects of technological changes on various socio-economic aspects of human life. The ramifications of the effects of large technological shocks are generally far from confined to strict realm of economics. ${ }^{15}$ These complicated chain of effects call for "quantitative-theoretical history," that is, the use of structural models allowing for an analysis of both the qualitative and the quantitative effects of technological shocks. ${ }^{16}$ The chapter by Greenwood et al. (2021) illustrates this line of research exploring specifically the effects of the transformation in contraceptive technologies and their take up from 1900 to 2000. This transformation has led to a sexual revolution, which witnessed a rise in premarital sex and out-of-wedlock births, and a decline in marriage. These demographic phenomena in turn have had important effects on many aspect of social and economic interactions, e.g., in labor markets. The calibrated model fits well various empirical moments, including e.g., the decline of proportion of married people, the increase in out-of-wedlock births, and the rise in the share of sexually active single females.

\section{The Challenges of Historical economics}

In the previous discussion we aimed to show how methodologically rigorous and innovative the field of Historical Economics is and how interesting and promising its results are. However there are sizeable differences in topics and attitude to research between "economic historians" in the Cliometric tradition and the new wave of "historical economists" (or "economists" tout court) engaging in economic history (especially in Peristence Studies). In this section we better delineate these differences so that we can suggest strategies to bridge them.

\footnotetext{
${ }^{15}$ The Second Industrial Revolution (which brought electricity, the petrochemical industry, and the internal combustion engine) at the beginning of the twentieth century, for instance, arguably encouraged the rise of cities and suburbs and allowed women to enter the labor force, providing a catalyst for women's rights. A similar narrative applies regarding the advent of the Information age; see Greenwood (1997).

${ }^{16}$ Greenwood et al. (2021) refer to an extensive literature in "quantitative-theoretical history;" it suffices to cite Greenwood et al. (2005) on secular decline in fertility; Hansen and Prescott (2002) on the transition from the pre-industrial to the industrial era, from land- intensive to capitalintensive production technologies; Kopecky and Suen (2010) on the impact of the automobile on suburbanization between 1910 and 1970; and the literature surveyed by Hansen et al. (2021) in this Handbook.
} 
Economic historians tend to be inward looking: even when they take up important questions and issues, they tend to deal with them as part of the ongoing discourse within the discipline which seldom resonates outside it. A good example is the debate on Allen's view of England as a 'high wage economy', which is the cornersone of his interpretation of the causes of the industrial revolution Allen (2021). The hypothesis has triggered a lively debate among economic historians about the level of wages (Humphries, 2013; Allen, 2015), which has attracted very little interests among economists, in spite of its implications for a major issue in economic history. Economists on the other hand tend to favor big questions with clear present-day relevance. Some of their work spans literally thousands of years (Ashraf and Galor, 2013) and puts forward broad generalizations. As a consequence, they expose themselves to the criticisms to neglect the historical context while designing natural experiments (Dippel and Leonard, 2020) and to âcompress historyâ (Austin, 2008), viewing it as just a repository of events and/or as a source of instruments.

The sociology of history and economics as academic disciplines has amplified this cleavage between economic historians and historical economists, giving rise to what we have interpreted as attempts at the methodological acquisition of one discipline by the other. This cleavage played out most evidently in defining the study of institutions (Acemoglu et al., 2005b; Ogilvie and Carus, 2014). Institutions have been a main concern of economic historians since its beginning in the 19th century, with two widely different approaches. Some scholars described, with as many details as possible given the sources, the rules and the evolution of specific institutions, guilds, merchant companies etc. Others, more often than not inspired by Marxism, put forward broad generalizations about economics and politics. The early Cliometricians disliked both approaches, respectively as antiquarian and not scientific, and retreated towards strictly economic issues. Douglass North, himself a prominent member of the Cliometrician group, brought institutions back to the limelight, with two books (North and Thomas, 1973; North, 1981). His call for action was only slowly heeded by economic historians. They were reluctant to use quantitative methods for the study of institutions, arguably because they felt it very difficult to translate broad generalizations (e.g., extractive/inclusive, particularized/generalized institutions) and models of institutional change in terms of source-compatible research questions. Indeed, many original documents on institutions have been lost and anyway written sources are unlikely to shed light on key features (tacit knowledge, network effects, cultural influences etc.). Economic historians thus preferred a softer rhetoric, based 
on general statements supported by selected examples. If pressed to generalize, they painted broad historical canvases. Economists, on the contrary, often deemed the price in terms of historical accuracy worth paying if the evidence is consistent with theoretical generalizations. A good example is the analysis of origin of the economic decline of the Venetian Republic (the Serenissima), which Acemoglu and Robinson (2012) see in its turn into a oligarchic institutional system from the Serrata del Gran Consiglio (1297). While consistent with theory of the role of the extractive/inclusive institutions dichotomy to explain economic growth Acemoglu et al. (2001, 2005b), this narrative is in contrast with the evidence that the institutions of the Serenissima lead its transition from a commercial to an industrial power in the Seventeen century (Rapp, 1976). ${ }^{17}$ Another significant example of the difference is the debate on guilds, a quintessential economic institution of pre-industrial European cities. Guilds were formal associations of merchants or craftsmen which enjoyed monopoly of a specific activity (wholesale trade or production of goods and services for consumers). Conventional wisdom since the Enlightenment and Adam Smith was that their monopoly was economically harmful. Avner Greif (Greif, 1989, 1993) disagreed and argued that merchant guilds performed some useful tasks and buttressed this claim with the analysis of business practices of the (Jewish) Maghribi traders in medieval Cairo and Genoese merchants. He argues that the Maghribi traders were a closely-knit group who enforced contracts via reputational effects, contrasting them with Genoese traders, who settled business controversies in courts. Ogilvie contested Greif's general views on merchant guilds in a book (Ogilvie, 2011) and his reconstruction of the business practices of the Maghribi traders in an article (Edwards and Ogilvie, 2012); Greif refuted the criticism and presents additional pieces of evidence supporting his analysis (Greif, 2012). Oglivie and Greif use the same set of business letters, but Greif looks at the general pattern in the documents, guided by his theoretical structure, while Edwards and Ogilvie focus on the details of interpretation of some of them.

Without taking a stand, we would like to highlight how this debate points to a silver lining in the cleavage between different approaches we have identified. Indeed there are a promising signs of methodological convergence - a path to a fruitful methodological merger of disciplines. For instance, while in her earlier book Ogilvie

\footnotetext{
${ }^{17}$ The origin of the decline of Venice can then be identified with the plague of 1630 , which hit Northern Italy with special strength (Alfani, 2013; Alfani and Murphy, 2017). Another competing narrative has the discovery of the Americas as a fundamental cause of the decline of the economic power of Venice (Borlandi, 1964; Braudel, 1972; O'Rourke and Williamson, 2009).
} 
relies, in the traditional approach to institutions taken by economic historians, on generalizations supported by anecdotal evidence, in her more recent book on artisanal corporations (Ogilvie, 2019), she has made an admirably massive effort to collect qualitative and quantitative information on the rules and activities of these institutions, a total of over 17,000 pieces. She is thus able to construct systematic tables of statistics. which may fall short of the requirements for econometrics analysis but are much more convincing for an economist than a single example. ${ }^{18}$

More generally, beyond this instance, the economists' demand for quantification of institutions (and not only of institutions) is pushing economic historians out of their comfort zone, with very promising results. For instance, they have succeeded to measure the influence of Parliaments in Medieval and early modern Europe. They were assemblies of representatives of the elites, which had some power to authorize the ruler(s) to impose new taxes, and thus could act as a constraint to the executive. ${ }^{19}$ Van Zanden et al. (2012) measure the Parliaments' power with the number of years of their meeting per century and find a positive relation with economic growth, as measured by city growth. Their proxy shows that power of parliaments grew all over Europe until the 16th century, while afterwards it continued to rise in NorthWestern Europe and declined sharply elsewhere (the French Etats Generaux were not convened from 1688 to 1789). Henriques and Palma (2019) use a more precise measure of parliamentary activity, as well as information on fiscal conditions of the state, to compare England with Spain and Portugal. They find, in contrast with Acemoglu et al. (2005a), that English institutions were not better than Spanish and Portuguese ones until the late 17th century. The case of the Polish parliament (Seijm) shows that too much constraint to the executive may be counterproductive as well (Malinowski, 2019): since 1652, each member had a veto power and this progressively paralyzed the legislative activity of the parliament. The uncertainty in property rights reduced the integration of domestic market, with negative consequences for the economy. The Polish-Lithuanian commonwealth became politically and militarily weaker and weaker in the 17th and 18th centuries and was ultimately carved between Russian, Prussian and Habsburg empires.

\footnotetext{
${ }^{18}$ Nonetheless, this does open issue of representativeness: Paris had 100 guilds in 1261-71 and 133 in 1766; if all information referred to Paris guilds only, which is clearly not the case, it would amount to one piece every four years.

${ }^{19}$ Notably, North and Weingast (1989) argued that the conditions imposed by the English Commons to the new king William III in 1688 marked a watershed in protection of property rights and the credibility of state commitments and that this institutional change fostered the development of financial system and of the military power of the kingdom.
} 
Economists, on their part, have been very creative and innovative in the use of interesting variables as instruments (formally and metaforically) for their analysis of the effects institutional change. In this respect, the real game changer has been the publication of Acemoglu et al. (2001) who came from different traditions. They were not surely the first to argue that colonial institutions had an important effect on economic growth, especially in Africa, nor they buttressed this claim with any structural modeling. The real novelty was the use of econometrics to test their claim - and especially of an Instrumental Variable approach to tackle the issue of endogeneity. The Instrumental Variable they used is 'settlers' mortality,' a measure of the pattern of settlement of Western colonists which determined the quality of colonial institutions. In their interpretation, higher settlers' mortality encodes for low-quality (extractive) institutions. This combination of wide ranging plausible hypothesis and empirical testing with panel regression has become the standard in the recent work by historical economists on institutional change, with the introduction of an innovative and interesting series of instruments, including: genetic diversity for social conflict and trust in Ashraf and Galor (2013), pogroms for anti-semitism in Voigtländer and Voth (2012), plow-suitability of the terrain for gender roles in Alesina et al. (2013b), and the list could continue a long way. Not all the instruments and data used by economists would pass a stringent test for historical accuracy, but this work should constitute at least valuable food for thought for more traditional economic historians (Dippel and Leonard, 2020).

The issue of quantity and quality of data emerges from this sketch as the key challenge for historical economists. Without data, you cannot address a lot of highly significant questions for the interpretation of the past and of its effect on the present and thus all historical economists agree that some compromise about their quality is necessary. However, economic historians tend to be more knowledgeable about the limitation of specific data. The most egregious example is the Atlas of World Population History (Jones, 1978), which is still widely and often a-critically used in Historical economics. It reports crude estimates, with almost no support reference, at long term intervals. By the time of publication it was a bold venture: we still have very limited and crude data on population before the 19th century for advanced countries and before the second half of the 20th for most of the others. However, at least for some countries, we have more fine-grained and reliable data. For instance, Broadberry et al. (2015) estimate a yearly series of the British population from 1270 onwards, based on twelve benchmark estimates between 1250 and 1522 and on the 
monumental work by Wrigley and Schofield (1981) from 1541.

Economic historians would call for some caution in using two other standard sources, the Ethnographic Atlas (Murdock, 1967) and the data-base for Global Agroeconomic zones, built by FAO and IIASA (Fischer et al., 2012). As said, the data from Ethnographic Atlas have been essential for many recent works on Africa. Lowes (2021) reports the positive and reassuring results of some attempts to validate its information (most notably on the mapping of ethnic groups) with independent sources. However, this work leaves out other reasons for caution, most notably the lack of knowledge about who was collecting the information (Western travelers vs. professional anthropologists), for which purposes (scholarly endeavours versus tax collection) and how common were substantial forms of misunderstanding or outright misleading on the part of surveyed populations. Just to take an extreme example, would a village head disclose to a British colonial administrator their slave holding, knowing that slavery was strongly disapproved or even forbidden? The GAEZ maps the suitability of world soils to different crops at very high geographical detail and thus is widely used as totally exogenous instrument in historical analysis (Alesina et al., 2013b; Galor and Özak, 2014; Nunn and Qian, 2014). It is a really impressive work. It relies on data on temperature, amount of water, quality of soil, slopes and so on to estimate the suitability under five systems of water provision, rain-fed, rain-fed with conservation and three different irrigation systems. The low-input is meant to refer to traditional technology, without fertilizers or machinery and thus it is used in Historical Economics. As Giuliano and Matranga (2021) correctly point out, the present-day low input technology may not be representative of past one: the historical varieties of seeds could be less (more) suitable to a given environment. One might add that millennia of cultivation and specific investments might have altered some features of the soil and the present-day climate might not be representative of the past one. During the Younger Dryas (about 12900 to 11700 before present), climate was decidedly cooler than nowadays (Bowles and Choi, 2019) and thus GAEZ is bound to overstate the suitability of land during the Neolithic transition.

The issue of reliability of data extends to proxies, which are widely used in all Historical Economics literature. In his chapter Federico (2021) discusses at length the potential bias from using distance as proxy for transport costs and the ratio of custom revenues to imports as proxy for protection in gravity model of trade. The former assumes constant transport cost, while the latter tends to understate protection. Taken jointly, they give relatively more weight to technology than to policy decisions 
in determining barriers to trade. Another example is the use of urbanization rates as proxy for GDP in pre-industrial societies, as popularized by Acemoglu et al. (2005a). The relation was indeed positive until 1910, but it seems rather unstable in its strength between the Sixteen and the Nineteen centuries (Jedwab and Vollrath, 2015). ${ }^{20}$

In general, assessing the reliability of any specific set of data and keeping abreast of the fast progress in historical research is difficult. In a seminal and unfortunately overlooked paper, Feinstein and Thomas (2002) argued that producers of historical series should attach to their figures an explicit assesment of margin of errors. Following this advice, Federico and Tena-Junguito (2019) estimate the overall margin of error of their series of world trade as sum of the (independent) variance of individual country-series. Also, Broadberry (2021) gives some examples for estimates of GDP per capita from the Maddison project, with margin of errors ranging from the almost negligible (Netherlands 1650-1750) to the humongous (Japan 750-1150). In our opinion any systematic effort along these lines, requiring the joint work of economic historians and historical economists, would be extremely valuable for the discipline.

\section{Conclusions}

Historical Economics is a very promising and important field. As all interdisciplinary endeavors, it differs from its parent-fields. It differs from economic history for the breadth of research questions, which include political and social issues, and above all for its statistical methods, which rely heavily on causal inference and at times on structural modeling. Historical Economics differs also from economics in that the availability of data is a serious constraint. Economists have showed remarkable ingenuity in overcoming the constraint, but they could be more aware of the fundamental trade-off: dealing with 'large' issues with weak (to say the least) data vs limiting oneself to 'small' issues with accurate and reliable data.

The obvious winning strategy is a merger of disciplines, putting together economists, political scientists, and economic historians (as well as, in specific instances, anthropologists, sociologists, evolutionary biologists). Good Historical Economics needs a combination of the knowledge of sources and detailed historical events and phe-

\footnotetext{
${ }^{20}$ The relationship has become negative after World War Two, with cities growing relatively more in poorer countries, but this has no relevance for the use of the proxy, for pre-industrial times.
} 
nomena, the capability of distilling complex historical processes into a model to put forward alternative testable hypotheses, the statistical/econometric skills for identification, causal inference, structural estimation, and testing, the detailed knowledge of specific political and socio-economic institutions, an understanding of the role of cultural traits, e.g., ethnic/religious, and of their evolution.

This book is a step in this direction, and this Introduction written jointly by an economist and an historian, discussing the pitfalls of their own disciplines, should serve as a suggestion that the merger can be done, leaving aside acquisition attempts. 


\section{References}

Abramitzky, Ran and Leah Boustan (2017) "Immigration in American economic history," Journal of economic literature, Vol. 55, No. 4, pp. 1311-45.

Abramitzky, Ran, Leah Platt Boustan, Katherine Eriksson, James J Feigenbaum, and Santiago Pérez (2019a) "Automated linking of historical data," National Bureau of Economic Research.

Abramitzky, Ran, Leah Platt Boustan, Elisa Jácome, and Santiago Pérez (2019b) "Intergenerational Mobility of Immigrants in the US over Two Centuries,"Technical report, National Bureau of Economic Research.

Acemoglu, Daron (2012) "Introduction to economic growth," Journal of economic theory, Vol. 147, No. 2, pp. 545-550.

Acemoglu, Daron, Giuseppe De Feo, and Giacomo Davide De Luca (2020) "Weak states: Causes and consequences of the Sicilian Mafia," The Review of Economic Studies, Vol. 87, No. 2, pp. 537-581.

Acemoglu, Daron, Georgy Egorov, and Konstantin Sonin (2021) "Institutional change and institutional persistence," in Bisin, Alberto and Giovanni Federico eds. Handbook of Historical Economics, Amsterdam: Elsevier North Holland.

Acemoglu, Daron, Simon Johnson, and James Robinson (2005a) "The rise of Europe: Atlantic trade, institutional change, and economic growth," American economic review, Vol. 95, No. 3, pp. 546-579.

Acemoglu, Daron, Simon Johnson, and James A Robinson (2001) "The colonial origins of comparative development: An empirical investigation," American Economic Review, Vol. 91, No. 5, pp. 1369-1401.

- (2002) "Reversal of fortune: Geography and institutions in the making of the modern world income distribution," The Quarterly journal of economics, Vol. 117, No. 4, pp. 1231-1294.

Acemoglu, Daron, Simon Johnson, and James A Robinson (2005b) "Institutions as a fundamental cause of long-run growth," Handbook of economic growth, Vol. 1, pp. $385-472$. 
Acemoglu, Daron and James A Robinson (2012) Why nations fail: The origins of power, prosperity, and poverty: Currency.

Adena, Maja, Ruben Enikolopov, Maria Petrova, Veronica Santarosa, and Ekaterina Zhuravskaya (2015) "Radio and the Rise of the Nazis in Prewar Germany," The Quarterly Journal of Economics, Vol. 130, No. 4, pp. 1885-1939.

Alesina, Alberto, Paola Giuliano, and Nathan Nunn (2013a) "On the origins of gender roles: Women and the plough," The Quarterly Journal of Economics, Vol. 128, No. 2, pp. 469-530.

_ (2013b) "On the origins of gender roles: Women and the plough," The Quarterly Journal of Economics, Vol. 128, No. 2, pp. 469-530.

Alfani, Guido (2013) "Plague in seventeenth-century Europe and the decline of Italy: an epidemiological hypothesis," European Review of Economic History, Vol. 17, No. 4, pp. 408-430.

Alfani, Guido and Tommy E Murphy (2017) "Plague and lethal epidemics in the preindustrial world," the Journal of economic History, Vol. 77, No. 1, pp. 314-343.

Allen, Robert C (2001) "The great divergence in European wages and prices from the Middle Ages to the First World War," Explorations in economic history, Vol. 38, No. 4, pp. 411-447.

- (2015) "The high wage economy and the industrial revolution: a restatement," The Economic History Review, Vol. 68, No. 1, pp. 1-22.

- (2019) "Poverty and the Labor Market: Today and Yesterday," Annual Review of Economics, Vol. 12.

Allen, Robert Carson (2021) "The Interplay among Wages, Technology, and Globalization: The Labour Market and Inequality, 1620-2020," in Bisin, Alberto and Giovanni Federico eds. Handbook of Historical Economics, Amsterdam: Elsevier North Holland.

Angrist, Joshua D and Guido W Imbens (1995) "Identification and estimation of local average treatment effects,"Technical report, National Bureau of Economic Research. 
Angrist, Joshua D and Jörn-Steffen Pischke (2008) Mostly harmless econometrics: An empiricist's companion: Princeton university press.

(2014) Mastering'metrics: The path from cause to effect: Princeton University Press.

Ashraf, Quamrul and Oded Galor (2013) "The 'Out of Africa' hypothesis, human genetic diversity, and comparative economic development," American Economic Review, Vol. 103, No. 1, pp. 1-46.

Ashraf, Quamrul H., Oded Galor, and Marc Kemp (2021) "The Evolutionary Origins of the Wealth of Nations," in Bisin, Alberto and Giovanni Federico eds. Handbook of Historical Economics, Amsterdam: Elsevier North Holland.

Austin, Gareth (2008) "The âreversal of fortuneâthesis and the compression of history: Perspectives from African and comparative economic history," Journal of International Development: The Journal of the Development Studies Association, Vol. 20, No. 8, pp. 996-1027.

Barro, Robert J (1979) "On the determination of the public debt," Journal of political Economy, Vol. 87, No. 5, Part 1, pp. 940-971.

Barro, Robert J, Xavier Sala-i Martin et al. (1995) "Economic growth."

Bechtel, Michael M, Dominik Hangartner, and Lukas Schmid (2016) "Does compulsory voting increase support for leftist policy?" American Journal of Political Science, Vol. 60, No. 3, pp. 752-767.

Becker, Sascha O., Jared Rubin, and Ludger Woessmann (2021) "Religion in Historical Economics," in Bisin, Alberto and Giovanni Federico eds. Handbook of Historical Economics, Amsterdam: Elsevier North Holland.

Becker, Sascha O and Ludger Woessmann (2009) "Was Weber wrong? A human capital theory of Protestant economic history," The quarterly journal of economics, Vol. 124, No. 2, pp. 531-596.

Bisin, Alberto and Andrea Moro (2021) "LATE for History," in Bisin, Alberto and Giovanni Federico eds. Handbook of Historical Economics, Amsterdam: Elsevier North Holland. 
Bisin, Alberto, Jared Rubin, Avner Seror, and Thierry Verdier (2020) "Culture, Institutions and the Long Divergence," New York University, mimeo.

Bisin, Alberto, Avner Seror, and Thierry Verdier (2019) "Religious legitimacy and the joint evolution of culture and institutions," in Advances in the Economics of Religion: Springer, pp. 321-332.

Bisin, Alberto and Thierry Verdier (2017) "On the joint evolution of culture and institutions," Working Paper 23375, National Bureau of Economic Research. (2021) "Phase Diagrams in Historical Economics: Culture and Institutions," in Bisin, Alberto and Giovanni Federico eds. Handbook of Historical Economics, Amsterdam: Elsevier North Holland.

Blaydes, Lisa and Eric Chaney (2013) "The feudal revolution and europe's rise: Political divergence of the christian west and the muslim world before 1500 ce," American Political Science Review, Vol. 107, No. 1, pp. 16-34.

Bolt, Jutta and Jan Luiten Van Zanden (2014) "The M addison P roject: collaborative research on historical national accounts," The Economic history review, Vol. 67, No. 3, pp. 627-651.

Borlandi, Franco (1964) "L'età delle scoperte e la rivoluzione economica nel secolo XVI," Nuove questioni di Storia moderna.

Bowles, Sam, Sung-ha Hwang, Jung-Kyoo Choi, and Suresh Nadu (2021) "How institutions and cultures change: a bottom-up perspective," in Bisin, Alberto and Giovanni Federico eds. Handbook of Historical Economics, Amsterdam: Elsevier North Holland.

Bowles, Samuel and Jung-Kyoo Choi (2019) "The Neolithic agricultural revolution and the origins of private property," Journal of Political Economy, Vol. 127, No. 5, pp. 2186-2228.

Braudel, Fernand (1972) La Méditerranée et le Monde Méditerranéen à l'Epoque de Philippe II (1949) /The Mediterranean and the Mediterranean World in the Age of Philip II]: New York: Harper. 
Broadberry, Stephen (2021) "The Industrial Revolution and the Great Divergence: Recent Findings from Historical National Accounting," in Bisin, Alberto and Giovanni Federico eds. Handbook of Historical Economics, Amsterdam: Elsevier North Holland.

Broadberry, Stephen, Bruce MS Campbell, Alexander Klein, Mark Overton, and Bas Van Leeuwen (2015) British economic growth, 1270-1870: Cambridge University Press.

Brooke, John L (2014) Climate change and the course of global history: a rough journey: Cambridge University Press.

Cantoni, Davide and Noam Yuchtman (2020) "Historical Contingencies, Econometric Problems: The Analysis of Natural Experiments in Economic History," working paper, National Bureau of Economic Research.

— (2021) "Historical Natural Experiments: Bridging Economics and Economic History," in Bisin, Alberto and Giovanni Federico eds. Handbook of Historical Economics, Amsterdam: Elsevier North Holland.

Cioni, M, G Federico, and M Vasta (2021) "The two Revolutions in Economic History," in Bisin, Alberto and Giovanni Federico eds. Handbook of Historical Economics, Amsterdam: Elsevier North Holland.

Cioni, Martina, Giovanni Federico, and Michelangelo Vasta (2019) "Three Different Tribes: How the Relationship between Economics and Economic History Has Evolved in the 21st Century."

Clark, Gregory (2007) "The long march of history: Farm wages, population, and economic growth, England 1209-1869 1," The Economic History Review, Vol. 60, No. 1, pp. 97-135.

— (2014) "The industrial revolution," in Handbook of economic growth, Vol. 2: Elsevier, pp. 217-262.

— (2021) "Social Mobility in Historical Economics," in Bisin, Alberto and Giovanni Federico eds. Handbook of Historical Economics, Amsterdam: Elsevier North Holland. 
Conrad, Alfred H and John R Meyer (1958) "The economics of slavery in the ante bellum South," Journal of Political Economy, Vol. 66, No. 2, pp. 95-130.

Crafts, Nicholas and Pieter Woltjer (2020) "Growth accounting in economic history: findings, lessons and new directions," Journal of Economic Surveys.

Cunningham, Scott (2021) Causal inference: The mixtape: Yale University Press.

Dedinger, Béatrice and Paul Girard (2017) "Exploring trade globalization in the long run: The RICardo project," Historical Methods: A Journal of Quantitative and Interdisciplinary History, Vol. 50, No. 1, pp. 30-48.

Dell, Melissa (2010) "The persistent effects of Peru's mining mita," Econometrica, Vol. 78, No. 6, pp. 1863-1903.

Dell, Melissa and Pablo Querubin (2018) "Nation building through foreign intervention: Evidence from discontinuities in military strategies," The Quarterly Journal of Economics, Vol. 133, No. 2, pp. 701-764.

Deng, Kent (2014) "A survey of recent research in Chinese economic history," Journal of Economic Surveys, Vol. 28, No. 4, pp. 600-616.

Diamond, Jared, James A Robinson et al. (2010) Natural experiments of history: Harvard University Press.

Dippel, Christian and Bryan Leonard (2020) "Not-So-Natural Experiments in History."

Dow, Gregory K, Clyde G Reed, and Nancy Olewiler (2009) "Climate reversals and the transition to agriculture," Journal of Economic Growth, Vol. 14, No. 1, pp. $27-53$.

Edwards, Jeremy and Sheilagh Ogilvie (2012) "Contract enforcement, institutions, and social capital: the Maghribi traders reappraised 1," The Economic History Review, Vol. 65, No. 2, pp. 421-444.

Erdkamp, Paul (2016) "Economic growth in the Roman Mediterranean world: An early good-bye to Malthus?" Explorations in Economic History, Vol. 60, pp. 1-20.

Federico, Giovanni (2019) "Market Integration," in Diebolt, Claude and Mike Haupert eds. Handbook of Cliometrics, Berlin-Heidelberg: Springer. 
_ (2021) "The Development of Commodity Markets in History," in Bisin, Alberto and Giovanni Federico eds. Handbook of Historical Economics, Amsterdam: Elsevier North Holland.

Federico, Giovanni and Antonio Tena-Junguito (2019) "World trade, 1800-1938: a new synthesis," Revista de Historia Económica-Journal of Iberian and Latin American Economic History, Vol. 37, No. 1, pp. 9-41.

Feinstein, Charles H and Mark Thomas (2002) "A plea for errors," Historical Methods: A Journal of Quantitative and Interdisciplinary History, Vol. 35, No. 4, pp. $155-165$.

Fischer, Günther, Freddy O Nachtergaele, Sylvia Prieler, Edmar Teixeira, Géza Tóth, Harrij Van Velthuizen, Luc Verelst, and David Wiberg (2012) "Global agroecological zones (GAEZ v3. 0)-model documentation."

Fogel, Robert William (1964) Railroads and American economic growth: Johns Hopkins Press Baltimore.

Fogel, Robert William and Stanley L Engerman (1974) Time on the cross: The economics of American Negro slavery, Vol. 1: WW Norton \& Company.

Fouquet, Roger and Stephen Broadberry (2015) "Seven centuries of European economic growth and decline," Journal of Economic Perspectives, Vol. 29, No. 4, pp. $227-44$.

Fourie, Johan, Nonso Obikili et al. (2019) "Decolonizing with data: The cliometric turn in African economic history," Handbook of Cliometrics, pp. 1-25.

Frankema, Ewout (2021) "Africa In Flux! A Critical Assessment of the Renaissance of African Economic History," in Bisin, Alberto and Giovanni Federico eds. Handbook of Historical Economics, Amsterdam: Elsevier North Holland.

Friedman, Milton and Anna J Schwartz (1963) A Monetary history of the US 18671960: Princeton University Press.

Galor, Oded and Ömer Özak (2014) "DP10122 The Agricultural Origins of Time Preference." 
Giuliano, Paola and Andrea Matranga (2020) "Historical Data: Where to Find Them, How To Use Them," in Bisin, Alberto and Giovanni Federico eds. Handbook of Historical Economics, Amsterdam: Elsevier North Holland.

- (2021) "Historical data: where to find them, how to use them," in Bisin, Alberto and Giovanni Federico eds. Handbook of Historical Economics, Amsterdam: Elsevier North Holland.

Greenwood, Jeremy (1997) The third industrial revolution: Technology, productivity, and income inequality, No. 435: American Enterprise Institute.

Greenwood, Jeremy, Nezih Guner, and Karen Kopecky (2021) "The Wifeâs Protector: The Effect of Contraception on Marriage during the 20th Century," in Bisin, Alberto and Giovanni Federico eds. Handbook of Historical Economics, Amsterdam: Elsevier North Holland.

Greenwood, Jeremy, Ananth Seshadri, and Guillaume Vandenbroucke (2005) "The baby boom and baby bust," American Economic Review, Vol. 95, No. 1, pp. 183207.

Greif, Avner (1989) "Reputation and coalitions in medieval trade: evidence on the Maghribi traders," The journal of economic history, Vol. 49, No. 4, pp. 857-882.

(1993) "Contract enforceability and economic institutions in early trade: The Maghribi traders' coalition," The American economic review, pp. 525-548.

- (2012) "The Maghribi traders: a reappraisal? 1," The Economic History Review, Vol. 65, No. 2, pp. 445-469.

Guiot, Joel, Christophe Corona et al. (2010) "Growing season temperatures in Europe and climate forcings over the past 1400 years," PloS one, Vol. 5, No. 4, p. e9972.

Hall, George and Thomas Sargent (2021) "Debt and Taxes in Eight U.S. Wars and Two Insurrections," in Bisin, Alberto and Giovanni Federico eds. Handbook of Historical Economics, Amsterdam: Elsevier North Holland.

Hansen, Gary D and Edward C Prescott (2002) "Malthus to solow," American economic review, Vol. 92, No. 4, pp. 1205-1217. 
Hansen, Gary, Lee Ohanian, and Jaeyoung Jang (2021) "Structural methods in historical macroeconomics: New perspectives on long-run growth and fluctuations," in Bisin, Alberto and Giovanni Federico eds. Handbook of Historical Economics, Amsterdam: Elsevier North Holland.

Haupert, Michael J and Claude Diebolt (2019) Handbook of Cliometrics: Springer.

Heckman, James J and Sergio Urzua (2010) "Comparing IV with structural models: What simple IV can and cannot identify," Journal of Econometrics, Vol. 156, No. 1, pp. 27-37.

Henriques, Antonio and Nuno Pedro G Palma (2019) "Comparative European Institutions and the Little Divergence, 1385-1800."

Humphries, Jane (2013) "The lure of aggregates and the pitfalls of the patriarchal perspective: a critique of the high wage economy interpretation of the British industrial revolution," The Economic History Review, Vol. 66, No. 3, pp. 693-714.

Jedwab, Remi and Dietrich Vollrath (2015) "Urbanization without growth in historical perspective," Explorations in Economic History, Vol. 58, pp. 1-21.

Johnson, Noel D and Mark Koyama (2017) "States and economic growth: Capacity and constraints," Explorations in Economic History, Vol. 64, pp. 1-20.

Jones, Colin McEvedy (1978) "Richard. Atlas of World Population History."

Juhász, Réka (2018) "Temporary protection and technology adoption: Evidence from the napoleonic blockade," American Economic Review, Vol. 108, No. 11, pp. 3339 76 .

Keane, Michael P (2010) "Structural vs. atheoretic approaches to econometrics," Journal of Econometrics, Vol. 156, No. 1, pp. 3-20.

Kelly, Morgan (2019) "The standard errors of persistence," Working Paper DP13783, CEPR.

Kopecky, Karen A and Richard MH Suen (2010) "A quantitative analysis of suburbanization and the diffusion of the automobile," International Economic Review, Vol. 51, No. 4, pp. 1003-1037. 
Kuran, Timur (2012) The long divergence: How Islamic law held back the Middle East: Princeton University Press.

La Porta, Rafael, Florencio Lopez-de Silanes, Andrei Shleifer, and Robert W Vishny (1998) "Law and finance," Journal of political economy, Vol. 106, No. 6, pp. 11131155.

Lampe, Markus and Paul Sharp (2015) "Cliometric approaches to international trade," Handbook of cliometrics, pp. 295-330.

Levine, David and Salvatore Modica (2021) "State Power and Conflict Driven Evolution," in Bisin, Alberto and Giovanni Federico eds. Handbook of Historical Economics, Amsterdam: Elsevier North Holland.

Li, Xiaoyun, Chris J Bleakley, and Wojciech Bober (2012) "Enhanced beacon-enabled mode for improved IEEE 802.15. 4 low data rate performance," Wireless Networks, Vol. 18, No. 1, pp. 59-74.

Lowes, Sara (2021) "Ethnographic Data and Field Experiment in Historical Economics," in Bisin, Alberto and Giovanni Federico eds. Handbook of Historical Economics, Amsterdam: Elsevier North Holland.

Lowes, Sara and Eduardo Montero (2020) "Concessions, violence, and indirect rule: Evidence from the congo free state,"Technical report, National Bureau of Economic Research.

Lowes, Sara, Nathan Nunn, James A Robinson, and Jonathan L Weigel (2017) "The evolution of culture and institutions: Evidence from the Kuba Kingdom," Econometrica, Vol. 85, No. 4, pp. 1065-1091.

Lucas, Robert E Jr and Nancy L Stokey (1983) "Optimal fiscal and monetary policy in an economy without capital," Journal of monetary Economics, Vol. 12, No. 1, pp. 55-93.

Maddison, Angus et al. (1995) "Monitoring the world economy, 1820-1992."

Maddison, Angus (1991) Dynamic forces in capitalist development: A long-run comparative view: Oxford University Press, USA. 
Malinowski, Mikołaj (2019) "Economic Consequences of State FailureâLegal Capacity, Regulatory Activity, and Market Integration in Poland, 1505-1772," The Journal of Economic History, Vol. 79, No. 3, pp. 862-896.

Manioudis, Manolis and Dimitris Milonakis (2020) "Smithâs Wealth of Nations and the economic past: setting the scene for economic history?" The European Journal of the History of Economic Thought, pp. 1-22.

Margo, Robert (2021) "The Economic History of Economic History: The Evolution of a Field in Economics," in Bisin, Alberto and Giovanni Federico eds. Handbook of Historical Economics, Amsterdam: Elsevier North Holland.

Matis, Matt, Pablo Querubin, and Shanker Satyanath (2021) "Persistent Failure? International Interventions Since World War II," in Bisin, Alberto and Giovanni Federico eds. Handbook of Historical Economics, Amsterdam: Elsevier North Holland.

Matranga, Andrea (2017) "The Ant and the Grasshopper: Seasonality and the Invention of Agriculture."

Matranga, Andrea and Luigi Pascali (2021) "Archaeological Data in Historical Economics," in Bisin, Alberto and Giovanni Federico eds. Handbook of Historical Economics, Amsterdam: Elsevier North Holland.

Mayshar, Joram, Omer Moav, Zvika Neeman, and Luigi Pascali (2019) "The Origin of the State: Land Productivity or Appropriability?"Technical report, mimeo, Hebrew University of Jerusalem, University of Warwick, Tel-Aviv âS.

McConnell, Joseph R, Nathan J Chellman, Andrew I Wilson, Andreas Stohl, Monica M Arienzo, Sabine Eckhardt, Diedrich Fritzsche, Sepp Kipfstuhl, Thomas Opel, Philip F Place et al. (2019) "Pervasive Arctic lead pollution suggests substantial growth in medieval silver production modulated by plague, climate, and conflict," Proceedings of the National Academy of Sciences, Vol. 116, No. 30, pp. 1491014915.

McConnell, Joseph R, Andrew I Wilson, Andreas Stohl, Monica M Arienzo, Nathan J Chellman, Sabine Eckhardt, Elisabeth M Thompson, A Mark Pollard, and Jørgen Peder Steffensen (2018) "Lead pollution recorded in Greenland ice indicates 
European emissions tracked plagues, wars, and imperial expansion during antiquity," Proceedings of the National Academy of Sciences, Vol. 115, No. 22, pp. $5726-5731$.

Meissner, Christopher M (2014) "Growth from globalization? A view from the very long run," in Handbook of economic growth, Vol. 2: Elsevier, pp. 1033-1069.

Merlo, Antonio (2005) "Whither political economy? Theories, facts and issues."

Michalopoulos, Stelios and Elias Papaioannou (2017) The Long Economic and Political Shadow of History Volume I. A Global View: Centre for Economic Policy Research.

— (2020) "Historical legacies and African development," Journal of Economic Literature, Vol. 58, No. 1, pp. 53-128.

Mokyr, Joel (2021) "Attitudes, Aptitudes, and the roots of the Great Enrichment," in Bisin, Alberto and Giovanni Federico eds. Handbook of Historical Economics, Amsterdam: Elsevier North Holland.

Monnet, Eric and Fracois R. Velde (2021) "Money, Banking, and Old-School Historical Economics," in Bisin, Alberto and Giovanni Federico eds. Handbook of Historical Economics, Amsterdam: Elsevier North Holland.

Monnet, Eric and Francois Velde (2021) "Monetary Policy and Good Old Historical Economics," in Bisin, Alberto and Giovanni Federico eds. Handbook of Historical Economics, Amsterdam: Elsevier North Holland.

Murdock, George Peter (1967) "Ethnographic atlas."

North, Douglass C and Robert Paul Thomas (1973) The rise of the western world: A new economic history: Cambridge University Press.

North, Douglass C and Barry R Weingast (1989) "Constitutions and commitment: the evolution of institutions governing public choice in seventeenth-century England," The journal of economic history, Vol. 49, No. 4, pp. 803-832.

North, Douglass Cecil (1981) Structure and change in economic history: Norton.

Nunn, Nathan (2014) "Historical development," in Handbook of economic growth, Vol. 2: Elsevier, pp. 347-402. 
(2020) "The historical roots of economic development," Science, Vol. 367, No. 6485 .

- (2021) "History as evolution," in Bisin, Alberto and Giovanni Federico eds. Handbook of Historical Economics, Amsterdam: Elsevier North Holland.

Nunn, Nathan and Nancy Qian (2014) "US food aid and civil conflict," American Economic Review, Vol. 104, No. 6, pp. 1630-66.

Nunn, Nathan and Leonard Wantchekon (2011) "The slave trade and the origins of mistrust in Africa," American Economic Review, Vol. 101, No. 7, pp. 3221-52.

Ogilvie, Sheilagh (2011) Institutions and European trade: Merchant guilds, 10001800: Cambridge University Press.

— (2019) The European guilds: An economic analysis: Princeton University Press.

Ogilvie, Sheilagh and André W Carus (2014) "Institutions and economic growth in historical perspective," in Handbook of economic growth, Vol. 2: Elsevier, pp. 403-513.

O'Rourke, Kevin H (1997) "The European grain invasion, 1870-1913," Journal of Economic History, pp. 775-801.

O'Rourke, Kevin H and Jeffrey G Williamson (2009) "Did Vasco da Gama matter for European markets? 1," The Economic History Review, Vol. 62, No. 3, pp. 655-684.

Pascali, Luigi and Andrea Matranga (2021) "The use of archaeological data in historical economics," in Bisin, Alberto and Giovanni Federico eds. Handbook of Historical Economics, Amsterdam: Elsevier North Holland.

Persson, Torsten and Guido Tabellini (2021) "Culture, Institutions, and Policy," in Bisin, Alberto and Giovanni Federico eds. Handbook of Historical Economics, Amsterdam: Elsevier North Holland.

Rapp, Richard Tilden (1976) "Industry and Economic Decline in SeventeenthCentury Venice, Cambridge, Mass." 
Reiss, Peter C and Frank A Wolak (2007) "Structural econometric modeling: Rationales and examples from industrial organization," Handbook of econometrics, Vol. 6, pp. 4277-4415.

Rubin, Jared (2017) Rulers, Religion, and Riches: Why the West got rich and the Middle East did not: Cambridge University Press.

Satyanath, Shanker, Nico Voigtländer, and Hans-Joachim Voth (2017) "Bowling for fascism: Social capital and the rise of the Nazi Party," Journal of Political Economy, Vol. 125, No. 2, pp. 478-526.

De la Sierra, Raul Sanchez et al. (2014) "On the origin of states: Stationary bandits and taxation in eastern congo," Chicago: University of Chicago.

Squicciarini, Mara P and Nico Voigtländer (2015) "Human capital and industrialization: Evidence from the age of enlightenment," The Quarterly Journal of Economics, Vol. 130, No. 4, pp. 1825-1883.

Stasavage, David (2021) "Biogeography, Writing, and the Origins of the State," in Bisin, Alberto and Giovanni Federico eds. Handbook of Historical Economics, Amsterdam: Elsevier North Holland.

Townsend, Robert M (1993) The medieval village economy: A study of the Pareto mapping in general equilibrium models: Princeton University Press Princeton, NJ.

Valencia, Felipe (2021) "Historical Econometrics: Instrumental Variables and Regression Discontinuity Designs," in Bisin, Alberto and Giovanni Federico eds. Handbook of Historical Economics, Amsterdam: Elsevier North Holland.

Van Zanden, Jan Luiten, Eltjo Buringh, and Maarten Bosker (2012) "The rise and decline of European parliaments, 1188-1789 1," The Economic History Review, Vol. 65, No. 3, pp. 835-861.

Voigtländer, Nico and Hans-Joachim Voth (2012) "Persecution Perpetuated: The Medieval Origins of Anti-Semitic Violence in Nazi Germany*," The Quarterly Journal of Economics, Vol. 127, No. 3, pp. 1339-1392, URL: http://dx.doi. org/10.1093/qje/qjs019, DOI: 10.1093/qje/qjs019.

Voigtländer, Nico and Hans-Joachim Voth (2014) "Highway to hitler," National Bureau of Economic Research. 
Voth, Joaquim (2021) "Persistence - Myth and Mystery," in Bisin, Alberto and Giovanni Federico eds. Handbook of Historical Economics, Amsterdam: Elsevier North Holland.

Weisdorf, Jacob L (2005) "From foraging to farming: explaining the Neolithic Revolution," Journal of Economic surveys, Vol. 19, No. 4, pp. 561-586.

Williamson, Jeffrey G et al. (1974) Late nineteenth-century American development: a general equilibrium history: CUP Archive.

Williamson, Jeffrey G (1985) Did British capitalism breed inequality?: Allen and Unwin.

Wrigley, E Anthony and Roger S Schofield (1981) "The population of England 15411871-a reconstruction," London, Arnold. 